\title{
Smyrna/İzmir Agorası'nda Osmanlı Döneminin Günllük Yaşamından İzler
}

\section{Sevinç Gök*}

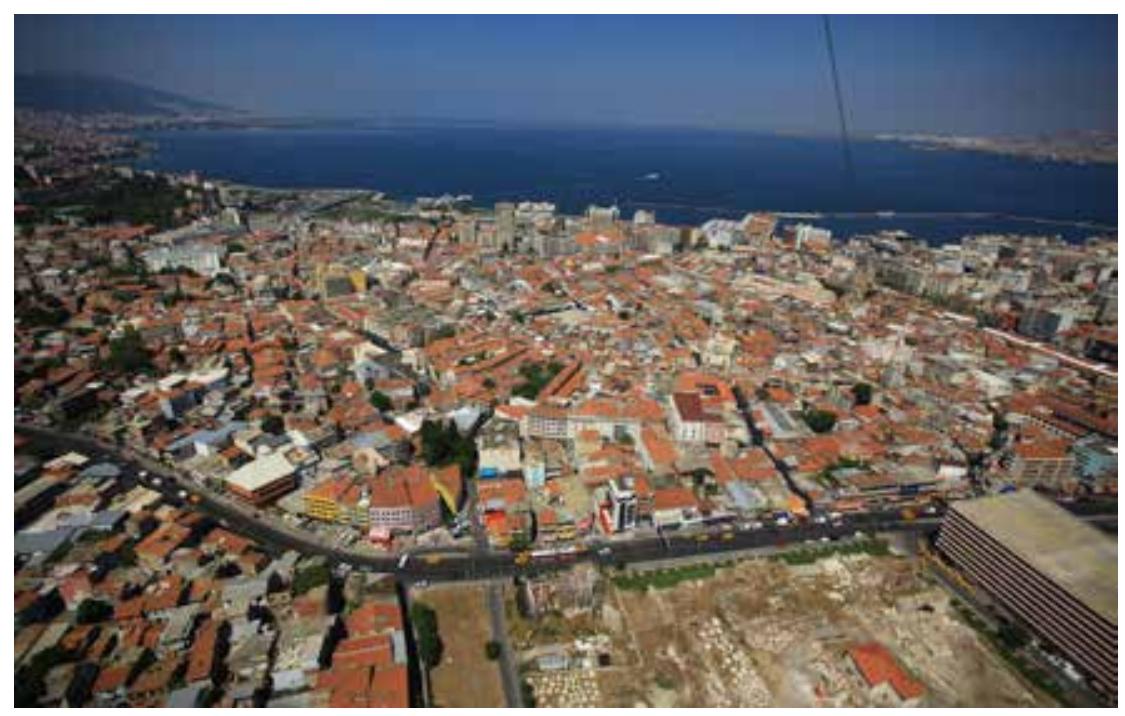

Fotoğraf 1. Smyrna Agorası ve Kemeraltı (Antik Smyrna Kenti Kazı Arşivi'nden)

Smyrna Antik Kenti Kazıları, Doç. Dr. Akın Ersoy'un başkanlığında, on iki yıldır aralıksız bir şekilde sürdürülmektedir.' Kazılar yalnızca Agora'daki antik yerleşim yapı ve kültür varlıklarını değil, Osmanlı dönemi yaşam izlerini de açığa çıkarmaktadır. Özenli ve sistematik kazılar, günümüze değin oluşan bütün kültür katmanlarının izlerini gözler önüne serer. Agora’nın avlu alanını çevreleyen antik yapılar üzerindeki Osmanlı yerleşimi, buluntularılla, özellikle 18-19. yüzyılların gündelik yaşamına ilişkin çok önemli bilgiler edinmemize de imkân sağlamaktadır (Fotoğraf 1-3).

Agora civarındaki demografik yapı karışıkıı. Evliya Çelebi kentin nüfusuyla ilgili "Bu şehrin tamamı on Müslüman mahallesi, on kefere zarbı, on Frenk ve Yahudi mahallesi, iki Ermeni ve bir Kıpti mahallesi vardır" ifadelerini kullanır. ${ }^{2}$ Agora'nın da bulunduğu alan Mezarlıkbaşı olarak geçer ve bu alanda Türk mezarlıkları yer alır. Mezarlığın batısı, yani İiçeşmelik Caddesi’ne bakan kesimde, Caves ve Bene Israel mahalleleri ile İkiçeşmelik'ten Kemeraltı'na geçişi sağlayan ve havraların yer aldığı, bugün de Havra Sokağı olarak anılan bölgede, Yahudi yerleşimi bulunur. 18. yüzyılda nüfusun artmasılyla Yahudi mahalleleri, Kadifekale eteklerine doğru genişlemiştir. Müslüman, Yahudi ve Rumların birbirine komşu olduğu, Kemeraltı'nın hemen üstünde, Havra Sokağı'nın kesişme noktasında yer alan Agora'nın avlu alanındaki Müslüman mezarlığının çevresinde, Yahudi ve Müslümanların yaşadığı anlaşılmaktadır.

Ne yazık ki Agora ve çevresindeki yerleşim hakkında çok net bilgiler yoktur. Avrupalı gezginler İzmir'i betimlerken Kadifekale'nin eteklerine yerleşmiş olan mahallelerden daha az bahse-

* Ege Üniversitesi, Sanat Tarihi Bölümü

1 Smyrna/İzmir Agorası için bkz. Akın Ersoy, Büyük İskender Sonrasında Smyrna (İzmir) (İzmir: İzmir Büyükşehir Belediyesi Kent Kitaplığı, 2015).

2 Abdullah Temizkan, Mertcan Akan, Kent ve Seyyah: Evliya Çelebi'nin Gözüyle Izmir ve Çevresi 1: Evliya Çelebi Seyahatnâmesi’nin Izmir Kısmının Transkripsiyonlu, Sadeleştirilmiş ve Orijinal Metni (İzmir: Ege Üniversitesi Basımevi, 2013), 29. 


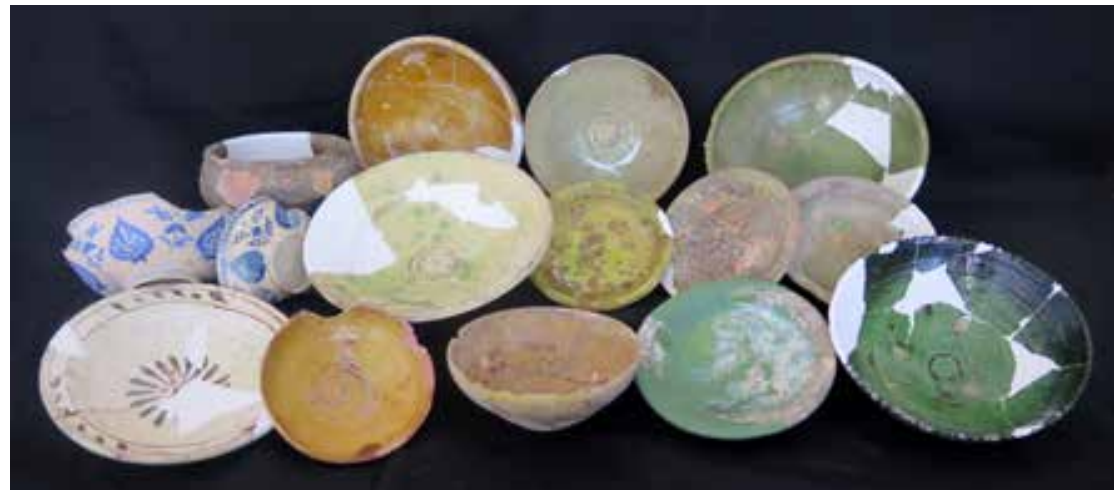

Fotoğraf 2. Smyrna/İzmir Agorası'nda bulunan Osmanlı Dönemi kapları (Fotoğraf: Sevinç Gök)

der. Onların ilgilendikleri alan daha çok liman bölgesi ve Frenk Mahallesi'dir. 1764 yılında İzmir'e gelen İngiliz gezgin Chandler, bu mahallelerin yeşil olduğunu, servilerin arasındaki evlerin üzerinden kubbe ve minarelerin yükseldiğini yazar. ${ }^{3}$ Sokakların darlığı, evlerin birbirine çok bitişik olduğu, üzerinde çok durulan konulardan biridir. Gezginler evleri, tek ya da iki katlı, kerpiçten ya da ahşaptan, kiremit çatılı, çoğunluğu bakımsız ve dayanıksız olarak tanımlar. ${ }^{4}$ Çoğu, yangın ve depremlerde harap olduktan sonra tekrar, bitişik nizam inşa edilmiştir.

Agora kazı alanında ortaya çıkarılan küçük buluntular, yaşamın nasıl idame ettirildiğini de gözler önüne serer. Gerek işyerlerinde gerekse evlerde, yeme, içme, ısınma, aydınlanma ve tuvalet gibi birçok alanda seramik malzeme kullanılmıştır (Fotoğraf 2-7).

Agora Kazısı'nda ortaya çıkarılan seramik kapların niteliği ve niceliği de bu alanda yaşayan halkın, yaşam tarzı ve beğenisi hakkında fikir edinmemizi sağlar. Osmanlı toplumunda, bugün de çoğu evde olduğu gibi yer sofrasında bir metal sini veya ahşap tabla ya da bir sofra bezi üzerinde aynı kap içerisinden yemek yendiği bilinmektedir. Bir gelenek olarak devam eden yerde yeme kültürünün, İzmir gibi kozmopolit bir kentte, Müslüman topluluğun yanı sıra ekonomik düzeye bağlı olarak Ermeni ve Musevi cemaat arasında da yaygın olduğu gezginlerin anlatımlarından anlaşılmaktadır. ${ }^{5}$

Kentte yaşayan, özellikle Levanten ve muhtemelen ekonomik düzeyi yüksek halkın, Avrupa gelenekleri çerçevesinde, masalarda, kişiye özel, farklı servis tabaklarında yemek yediği de

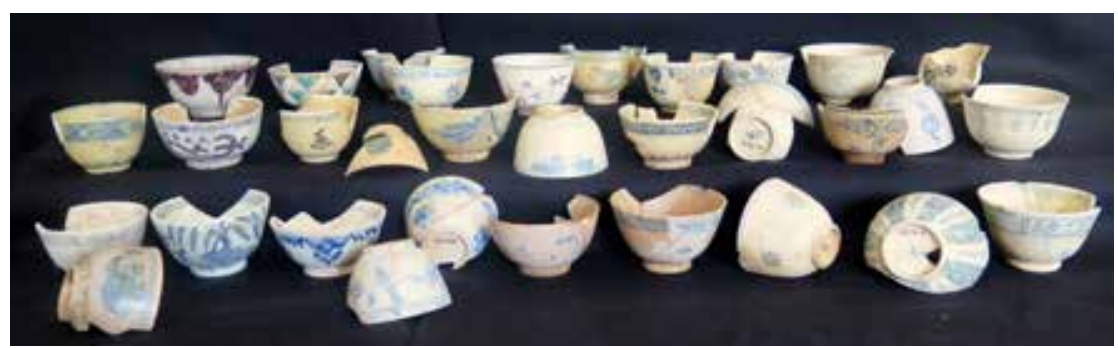

Fotoğraf 3. Smyrna/İzmir Agorası'nda bulunan Osmanlı Dönemi Kütahya fincanları (Fotoğraf Sevinç Gök)

3 Ayda Arel, "18. Yüzyılda İzmir Çevresinde Mimari Ortam”, 18. Yüzyılda Osmanlı Kültür Ortamı: Sempozyum Bildirileri, 20-21 Mart 1997 içinde (İstanbul: Sanat Tarihi Derneği Yayınları, 1998), 9-31, burada 29.

4 Hasan Zorlusoy, (XVII. Yüzyıldan Günümüze) FransIz Gezginlerin Gözüyle Izmir (İzmir: İzmir Büyükşehir Belediyesi Kent Kitaplığı, 2013), 132-136.

5 Rauf Beyru, 19. Yüzyılda Izmir'de Yaşam (İstanbul: Literatür Yayıncılık, 2000), 104, 106; Zorlusoy, Fransız Gezginlerin Gözüyle Izmir, 110. 

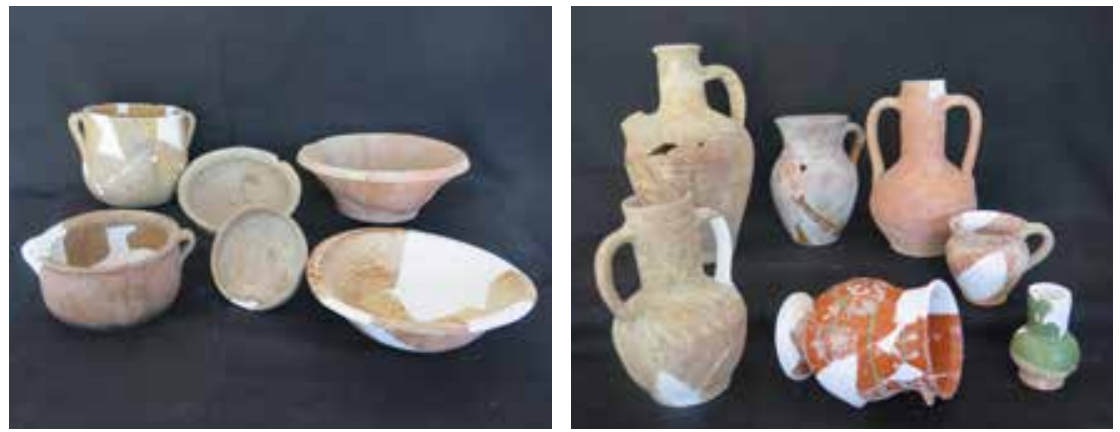

Fotoğraf 4-5. Smyrna/İzmir Agorası'nda bulunan Osmanlı Dönemi mutfak kapları (Fotoğraf: Sevinç Gök)

anlaşılmaktadır. Agora kazılarında yoğun miktarda bulunan ve Avrupa'dan ithal edilen tabak ve fincanların çoğunun takımlar halinde olması, yemeğin ister masada ister yerde Türk usulü yenilsin, sofra düzenlemesine özenildiğini düşündürmektedir ${ }^{6}$ (Fotoğraf 8). Osmanlı yerel üretim seramiklerinde de birbirine benzer tabaklar dikkati çeker.

Özellikle 18. ve 19. yüzyıl Osmanlı toplumunda, zengin ve üst düzey yönetici kesimin belli alışkanlıkları ve orta sınıf halktan bu alışkanlıklar açısından ayrılan yönleri bulunmaktaydı. Daha büyük evler ve konaklarda yaşayan erk sahibi kişi ve ailelerinin kullandıkları mutfak ve sofra kapları da farklılıklar göstermekteydi.

Özellikle tereke defterlerinde zengin ve mevki sahibi kişilerin mal beyanları yapılırken değerli kap türü olarak İznik seramiklerinin sayıldığı ya da gümüş tabak, çanak, sürahi, cezve, çatal, bıçak, kaşık, sini, testi vb. malzemelerden bahsedildiği görülmektedir.?

Agora'da bulunan Kütahya, Çanakkale ve İstanbul ile Gökeyüp, Menemen gibi yerel üretim merkezlerine ait çok sayıdaki tabak, çanak, kâse, güveç, tava, fincan, mangal, maltız (ısıtma kabı), kandil, şamdan ve havruzlar (lazımlık), irili ufaklı boyutlarılla çeşitlilik sunar ${ }^{8}$ (bkz. Fotoğraf 2-7). Bu kapların daha düşük alım gücüne hitap eden örnekler olması ise dikkat çekicidir. Agora kazılarında yoğun miktarda bulunan Avrupa seramiği, özellikle de serigrafi (transfer) baskılı örnekler de fabrikasyon üretimidir ve dönemi için nispeten ucuz mallardır (bkz. Fotoğraf 8).

Mutfak ve sofra kapları, evlerde hangi yemekler pişiriliyordu sorusunu da akla getirmektedir. Maalesef özellikle halkın ne yediğine ilişkin kayıt ve bilgi neredeyse yok gibidir. Osmanlı dönemi yeme kültürünü anlatan kitap ve yayınların çoğu saray mutfağından ya da şölenlerden bahseder. Halkın yeme alışkanlıklarını Osmanlı tarihçiliğinden pek öğrenemiyoruz. Gezginlerin anılarında ise genellikle ün yapmış yiyecek ve içeceklerin isimleri yer almaktadır. ${ }^{9}$ Gezginlerin verdiği bilgi-

6 Sevinç Gök, “Akdeniz Ticaretinin Önemli Belge Buluntuları: Seramikler”, Sanat Tarihi Dergisi, Cilt XX, No. 2 (2011): 61-100, burada 79-84.

7 Suraiya Faroghi, Osmanı Dünyasında Üretmek, Pazarlamak, Yaşamak, çev. Gül Çağalı Güven, Özgür Türesay, 3. baskı (İstanbul: YKY, 2008), 210, 258-259; Gülser Oğuz, "Tereke Kaydından Hareketle Bir Osmanlı Vezirinin 18. Yüzyıl Başlarındaki Yaşam Tarzl: Amcazâde Hüseyin Paşa”, Millî Folklor, YIl 22, No. 88 (2010): 91-100, burada 96-98; Meryem Koçan Erdoğan, "Mülteci Bir Macar Prensi ve Terekesi: Rakoczi Jozsef”, SDÜ Fen Edebiyat Fakültesi Sosyal Bilimler Dergisi, No. 23. (Mayıs 2011): 81-102, burada 96-97; Gökhan Civelek, "XVII. Yüzyıl Ortalarında Elit Bir Kadının Terekesi: Manastır’ı Aişe Hatun”, Atatürk Üniversitesi Edebiyat Fakültesi Sosyal Bilimler Dergisi, No. 54 (Haziran 2015): 241-260, burada 249; Sevinç Gök, “Osmanlı ve Avrupa Seramikleri Üzerinden Bir Okuma: Smyrna (İzmir) Agorası'ndaki Osmanlı Yerleşiminden Mutfak Kapları ile Günlük Yaşam Objeleri", Smyrna/İzmir Kazı ve Araştırmaları Il içinde, der. Burak Yolaçan, Gözde Şakar, Akın Ersoy (İstanbul: Ege Yayınları, 2017), 117-165.

8 Sevinç Gök, "Osmanlı ve Avrupa Seramikleri Üzerinden Bir Okuma”, 117-165; Sevinç Gök, Smyrna (İzmir) Agorası'nda Osmanlı İleri. Kütahya Seramikleri (2007-2014 Kazı Dönemi) (İzmir: İzmir Büyükşehir Belediyesi Kent Kitaplığı, 2015).

9 Zorlusoy, Fransız Gezginlerin Gözüyle Izmir, 143-145; Olaf Yaranga, XIX. Yüzylın IIlk Yarısında Fransız Gezginlerin Anlatımlarında İzmir, çev. Gürhan Tümer, 2. Basım (İzmir: İzmir Büyükşehir Belediyesi Kent Kitaplığı, 2002), 37. 

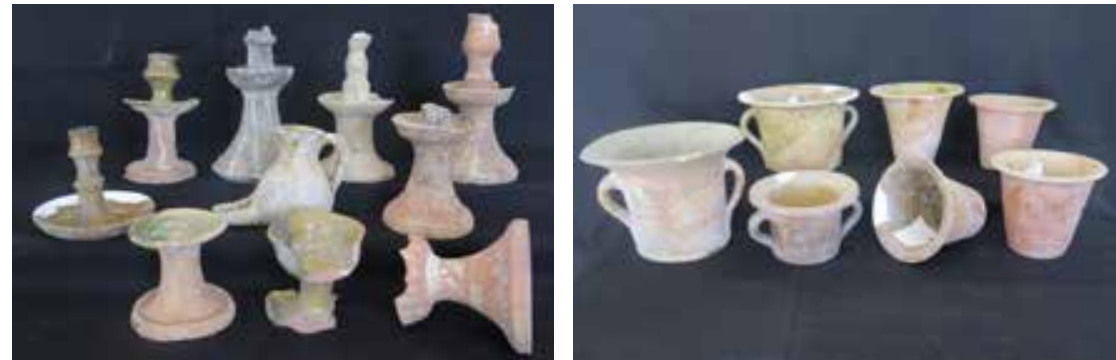

Fotoğraf 6-7. Smyrna/Izmir Agorası'nda bulunan Osmanlı Dönemi kandil ve lazımlıkları (Fotoğraf: Sevinç Gök)

ler oldukça değerlidir. Ancak bunların arkeolojik verilerle desteklenmesi de bizim için bir o kadar önemlidir.

Agora kazılarında ortaya çıkarılan yoğun miktarda kemik obje de yemek alışkanlıklarıyla ilgili çok önemli veriler sunar. Kemik objeler üzerinde arkeozoolojik araştırmalar yapan Prof. Dr. Vedat Onar'ın tespitlerinden, tüketim artığı kemikler dikkate alınarak Agora'da, sığır, koyun, keçi, domuz, kaz, tavuk, horoz, köpekbalığı, levrek, ton balığı, istiridye, müreks salyangozu, nuh tarağı, deniz tarağı, yumuşakça ve yabani tavşan gibi hayvanların tüketildiği ve aynı zamanda bunların kemiklerinin de kullanılmasıyla objeler üretildiği anlaşılmaktadır.10

Onar'ın tespit ettiği hayvanlar ile gezginlerin gözlemlediği yiyecekler, neredeyse tamamen örtüşmektedir. Verimli toprakları, muhteşem körfezi, ticaret faaliyetleri ile hinterlandın geniş olduğu bu kentte, her türlü yiyecek ürününün bulunması şaşırtıcı değildir. Kozmopolit bir şehir olan İzmir'de, birçok kentin ve kültürün yemek özelliklerinin bir araya geldiği de kesindir. Onar ayrıca, bazı kemiklerin ısıya maruz kaldığını da tespit etmiştir. Bu da etlerin ızgarada pişirildiğine işaret etmektedir. Seyyahların İzmir ile ilgili anlatımlarında buğday ve pirinç gibi bakliyatların yanı sıra köfte, kızarmış tavuk, pilav, sarma, taze fasulye, sebzeli börek, lahana dolması ve enginar gibi yemekler ile helva ve baklavadan sıklıkla bahsedildiği dikkati çekmektedir.11

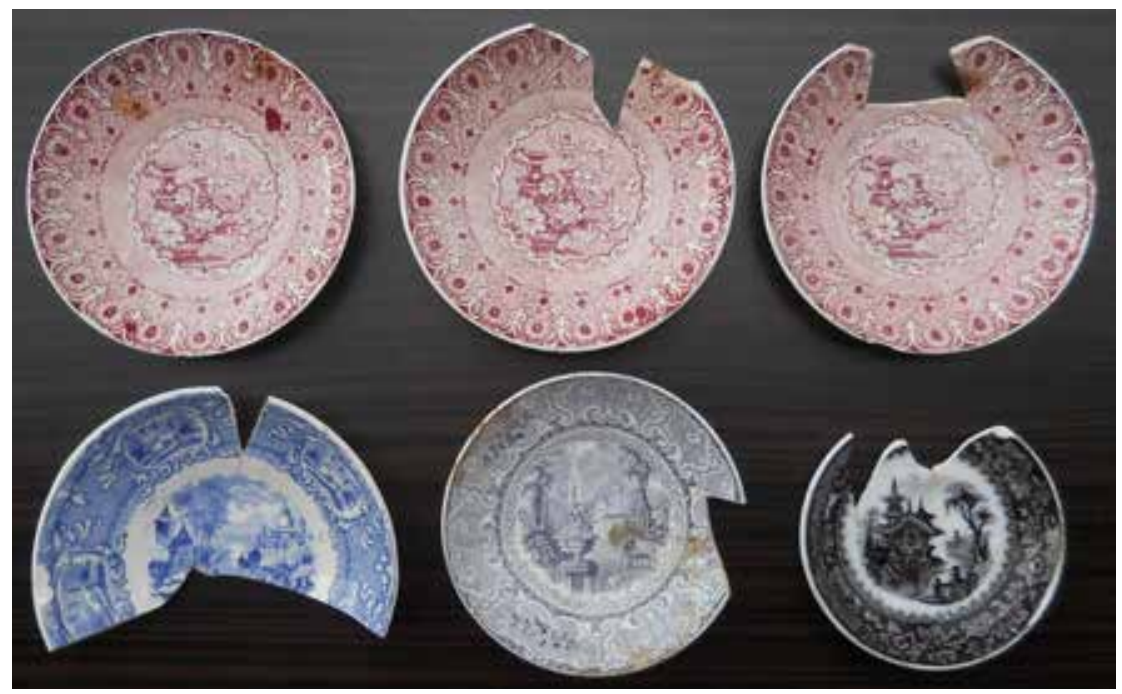

Fotoğraf 8. Smyrna/İzmir Agorası'nda bulunan Avrupa seramikleri (Fotoğraf: Sevinç Gök)

10 Akın Ersoy, Antik Dönemden Osmanlı Dönemine: Smyrna/Izmir Kemik Objeleri (İstanbul: Ege Yayınları, 2017), 85-98.

11 Yücel Özkaya, 18. Yüzyılda Osmanlı Toplumu, 2. Baskı (İstanbul: YKY, 2010), 341-342. 


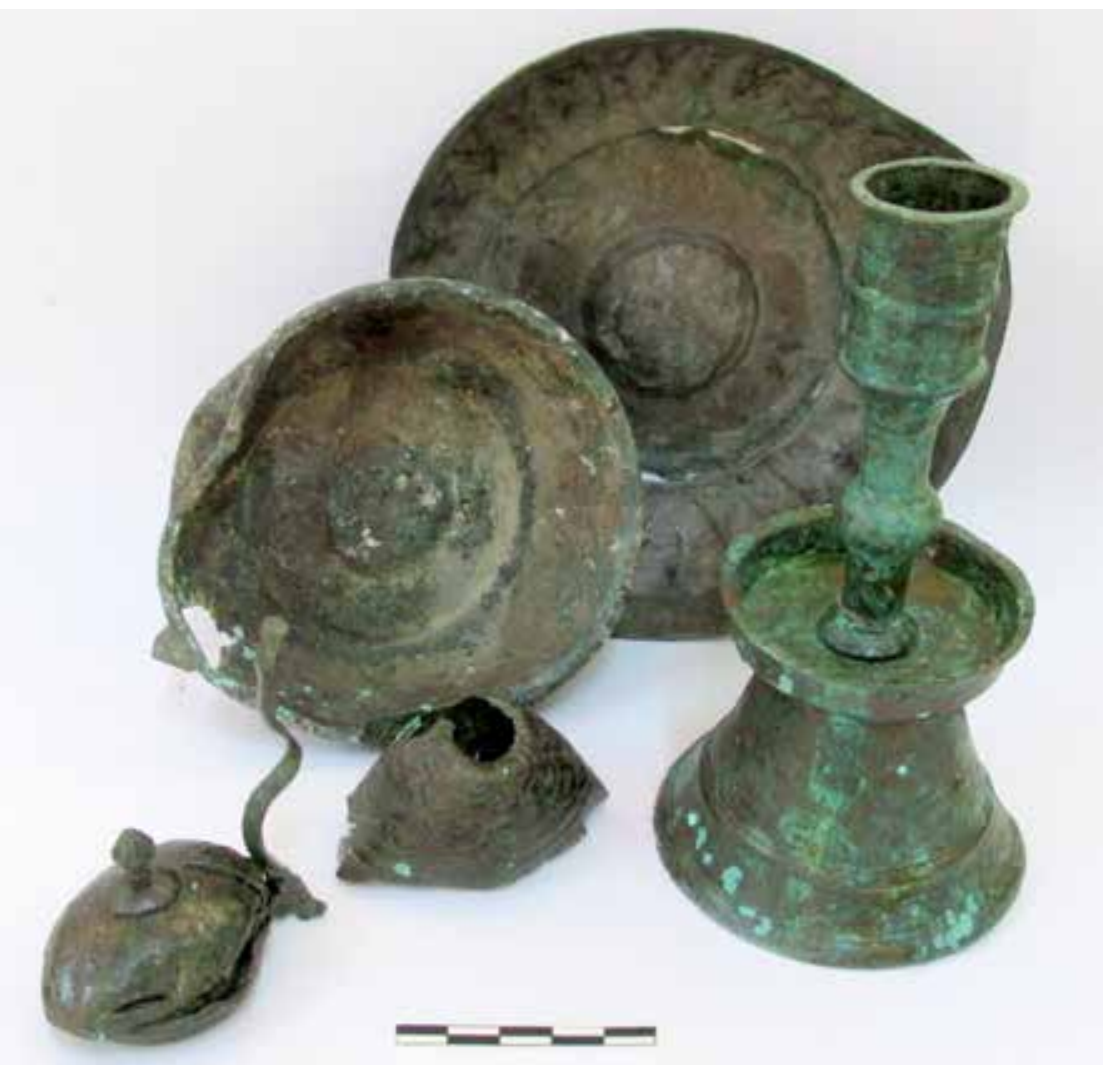

Fotoğraf 9. Smyrna/Izmir Agorası'nda bulunan metal kaplar (Antik Smyrna Kenti Kazı Arşivi'nden)

Yahudi cemaatinin ilk yerleşim alanı olan ve geleneksel yaşamın yaklaşık 300 yıl devam ettiği Agora'da, özellikle Yahudilerin gerileme dönemi olarak nitelendirilen 18. yüzyıldan itibaren halk yoksullaşmaya başlamıştır. Agora'daki buluntular değerlendirildiğinde, dönemi için orta halli halkın kullanabileceği, çeşitli seramiklerle günlük hayatın idame ettirildiği bir tablo ortaya çıkmaktadır. Osmanlı yerli üretim seramikleri ile Avrupa'dan ithal örneklerin bir arada kullanıldığı bu alanda, dönemi için pahalı olmayan, her kesimin rahatlıkla temin edebileceği örneklerin olması, ekonomik düzey ile bağlantılı olmalıdır. Kazılarda ortaya çıkarılan metal, cam, kemik gibi farklı malzemeli objeler de bu görüşlerimizi destekler niteliktedir ${ }^{12}$ (bkz. Fotoğraf 9). Ayrıca, civarda yer alan ticaret hayatıyla ilgili bilgiler de ekonomik düzeyi belirleyecek bilgiler içerir. Çınar Atay, Büyük Leblebici Hanı, Kiraz Hanı, Yemişçizade Hanı, Paşa Hanı, Güven Hanı ve Menzil Hanı gibi Mezarlıkbaşı civarında kurulmuş hanlarda, daha düşük gelire sahip insanlara yönelik satışların yapııdığını ve satışı yapılan ürünlerin de birinci kalite olmadığını belirtir.13

Sonuç olarak, Osmanlı devletinin kozmopolit yapısı içerisinde Müslüman, Yahudi, Ermeni ve Rum toplulukları ile Levantenlerin bir arada yaşadığı kentte Agora ölçeği, halkın yaşam tarzı ve sosyo-ekonomik düzeyi hakkında bir çerçeve çizebilmemize imkân sağlamıştır.

12 Binnur Gürler, Akın Ersoy, Gülten Çelik Ersoy, Izmir'in Osmanı Dönemi Tanıkları: Smyrna/lizmir Agorası'ndan Cam Objeler (İzmir: İzmir Büyükşehir Belediyesi Kent Kitapları, 2016); Ersoy, Antik Dönemden Osmanlı Dönemine: Smyrna/lizmir Kemik Objeleri.

13 Çınar Atay, "Kapanan Kapılar": İzmir Hanları (İzmir: İzmir Büyükşehir Belediyesi Kent Kitapları, 2003), 116, 119, $122,124-125,127$. 